HNO $2021 \cdot 69$ (Suppl 2):S35-S38

https://doi.org/10.1007/s00106-021-01070-9

Accepted: 7 May 2021

Published online: 16 July 2021

(c) The Author(s) 2021

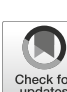

\section{Recommendations for use of topical inhalant budesonide in COVID-19}

Ludger Klimek' $\cdot$ Roland Buhl ${ }^{2}$. Thomas Deitmer ${ }^{3}$. Stefan Plontke .

Wolfgang Wehrmann ${ }^{5} \cdot$ Hans Merk $^{6} \cdot J^{\prime}$ Johnnes Ring ${ }^{7} \cdot$ Sven Becker ${ }^{8}$ Ärzteverband Deutscher Allergologen (AeDA) · Deutsche Gesellschaft für Hals-Nasen-OhrenHeilkunde, Kopf- und Hals-Chirurgie (DGHNO-KHC)

'Zentrum für Rhinologie und Allergologie Wiesbaden, Wiesbaden, Germany

${ }^{2}$ Schwerpunkt Pneumologie, III. Medizinische Klinik und Poliklinik, Universitätsmedizin Mainz, Mainz, Germany

${ }^{3}$ Deutsche Gesellschaft für Hals-Nasen-Ohren-Heilkunde, Kopf- und Hals-Chirurgie, Bonn, Germany

${ }^{4}$ Klinik und Poliklinik für Hals-Nasen-Ohren-Heilkunde, Kopf- und Hals-Chirurgie, Martin-LutherUniversität Halle-Wittenberg, Halle, Germany

${ }^{5}$ Dermatologische Gemeinschaftspraxis Wehrmann, Münster, Germany

${ }^{6}$ Abteilung Dermatologie \& Allergologie, RWTH Aachen, Aachen, Germany

${ }^{7}$ Haut- und Laserzentrum an der Oper, Munich, Germany

${ }^{8}$ Klinik für Hals-, Nasen- und Ohrenheilkunde, Kopf- und Halschirurgie, Eberhard Karls Universität Tübingen, Tübingen, Germany
The German version of this article can be found under https://doi.org/10.1007/s00106021-01084-3.

Members of the German Society for Applied Allergology (AeDA) and the German Society of Oto-Rhino-Laryngology, Headand NeckSurgery (DGHNO) will be mentioned at the end of the article.

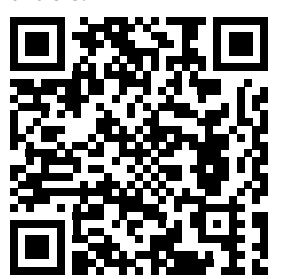

Scan QR code \& read article online
Inhalational glucocorticosteroids (ICS) are considered standard therapy for inflammatory diseases of the airway mucosa, such as allergic rhinitis (AR), chronic rhinosinusitis (CRS), or bronchial asthma ( $A$; [1, 2]). Chronic rhinosinusitis, $A R$, and $A$ are among the most common inflammatory diseases, and chronicity is often associated with epithelial damage and tissue destruction that can promote viral infections [1, 2].

Bronchial asthma is an important comorbidity of AR and CRS. Deterioration in the control of $A R$ and CRS may promote asthma exacerbations [3-7].

After indications were initially published in the current SARS-CoV-2 pandemic that "cortisone preparations" could increase the risk of contracting COVID19 or cause a more severe course of the disease and thereby massively unsettled numerous patients with $A R, C R S$, and asthma. Position papers of the German and European societies pointed out the necessity of continuing therapy with topical GCS very early in the pandemic [1, 2]. Accordingly, ICS and nasal GCS (nGCS) are effective in the treatment of mucosal inflammation of the upper and lower respiratory tract and represent the standard therapy for these conditions [8-11].

No evidence exists to suggest that use of nGCS and ICS triggers an increased risk of SARS-CoV-2 infection or a more severe course of COVID-19-disease. Therefore, adults and children with AR, CRS, and A should consistently and regularly take their prescribed nGCS and ICS at the individually prescribed dose and not change or even discontinue them without consulting the treating physician $[1,2]$. Here, we also point out that effective anti-inflammatory control of the upper and lower airways by topical GCS is a good protection against viral-triggered exacerbations for these patients according to current medical knowledge[1,2]. From today's perspective, there are sufficient data that patients 
with chronic inflammatory airway disease should receive guideline-based pharmacologic treatment in the context of the COVID-19 pandemic, including nGCS, ICS, and biologic therapies if needed $[12,13]$. The aforementioned topical GCS include budesonide.

\section{Study on the use of budesonide in COVID-19}

In the latest issue of The Lancet Respiratory Medicine, Ramakrishnan et al. published a hypothesis-generating study on the use of inhaled budesonide versus "standard therapy" in patients with early COVID19 [14]. The authors conducted a phase 2 , open-label, randomized controlled, parallel-group study to compare the use of inhaled budesonide $(1600 \mu \mathrm{g} /$ day $)$ with standard therapy in patients with symptomatic COVID-19 established in the past 7 days [14]. The authors concluded that this treatment regimen may be the first cost-effective and readily available therapeutic intervention for early-stage COVID-19. They mention that their data may also represent a potentially effective treatment for preventing long-term and persistent COVID19 symptoms.

\section{Evaluation of the study data}

In our opinion, the above statements [14] are not supported by the data presented. This was an open-label study in which patients and physicians were informed about the type of therapy. Placebo effects of ICS in bronchial asthma have been described at a rate of $21-46 \%$, especially when subjective outcome parameters are used as evaluation criteria (outcome parameters; [15]).

The effects observed in this study, including the primary endpoint (COVID-19related outpatient presentation or hospitalization) and secondary endpoints (such as time to clinical improvement subjectively perceived by patients) may have been influenced by the subjective perceptions of affected patients and their treating physicians [16].

Objective measures such as blood oxygen saturation, body temperature, spirometry findings, and quantitative viral load with SARS-CoV-2 were used as addi- tional secondary endpoints in the study, but the results did not differ between groups. The study was small and included only 146 participants - 73 were randomized to the "standard therapy" and 73 to the budesonide group.

Ramakrishnan et al. hypothesized that early administration of inhaled budesonide would reduce the likelihood of needing urgent medical care and shorten the time to recovery for patients with COVID-19 treated early [14]. Given the evidence from this and other studies, this interpretation of the data remains speculative.

The primary endpoint was met in 11 (15\%) control patients and two (3\%) budesonide patients $(p=0.009)$. Time to clinical improvement was 1 day shorter in the budesonide-treated patients (7 vs. 8 days, $p=0.007$ ). Fever occurred in $2 \%$ of the budesonide patients in the 14 days after study entry compared with $8 \%$ of the control patients $(p=0.051)$. Adverse effects occurred in five patients $(7 \%)$ of the budesonide group.

This fits with the interim results of a still-ongoing larger phase III trial of 2617 patients, also testing inhaled budesonide therapy for acute SARS-CoV-2 infection [17]. This showed a 3-day shorter time to self-reported clinical improvement of symptoms, but the small effect on COVID-19-related hospitalizations or deaths (budesonide: 59/692 [8.5\%] vs. $100 / 968$ [10.3\%] patients) was not statistically significant.

\section{Discussion}

The German societies AeDA (German Society for Applied Allergology), DGP (German Respiratory Society), DGAKI (German Society for Allergology and Clinical Immunology), and DGHNO (German Society of Oto-Rhino-Laryngology, Head and Neck Surgery) together with international organizations such as ARIA (Allergic Rhinitis and Its Impact on Asthma Initiative), EAACI (European Academy of Allergy and Clinical Immunology), and GAL²EN (Global Allergy and Asthma European Network) emphasized the need for continuation and consistent use of ICS in patients with inflammatory airway diseases early in the pandemic $[12,13]$. Similar recommendations were also made for other allergic diseases during the pandemic [18-20].

The available study results on inhaled budesonide therapy suggest that a somewhat shorter symptom duration can be achieved when high-dose inhaled budesonide therapy is started within a few days after the onset of COVID-19 disease. A higher-grade clinical effect cannot be demonstrated on the basis of current study data.

A cautious interpretation of these data is all the more warranted given that an updated interim analysis of data from a larger phase III trial that included 2617 participants with risk factors for unfavorable outcomes with COVID-19 did not show such favorable results [17]-inhaled budesonide shortened time to selfreported recovery by a median of 3 days, but did not meet the primary outcome parameter (predefined superiority threshold for the probability that COVID-19 hospitalizations/deaths were lower in the budesonide group compared with standard therapy): budesonide: 59/692 (8.5\%) vs. standard therapy: $100 / 968$ (10.3\%) [17].

Recent data provide further evidence that patients with different asthma endotypes (type 2 asthma vs. non-type 2 asthma) have different risk profiles with respect to SARS-CoV-2 infection, development of COVID-19, and progression to severe COVID-19 disease [21].

Effective measures to contain the pandemic, on the other hand, are restrictions on social life, especially to protect vulnerable patient groups and to maintain a functioning healthcare system. In agreement with the German Robert Koch Institute (RKI) and the World Health Organization (WHO), we recommend preventive measures in the current pandemic situation, such as [22-25]:

- Keeping a distance of at least 1.5-2 m from other people

- Adherence to general hygiene measures, such as regular hand disinfection/regular hand washing for at least 30 s, avoid touching mucous membranes with hands

- Minimizing social contact

- Limiting personal patient contacts to what is absolutely necessary

- Wearing personal protective clothing 
- Regular surface disinfection, especially door handles, etc.

- Vaccination campaigns that are as rapid and comprehensive as possible

Corresponding address

PD Dr. Sven Becker

Klinik für Hals-, Nasen- und Ohrenheilkunde, Kopf- und Halschirurgie, Eberhard Karls Universität Tübingen

Elfriede-Aulhorn-Str. 5, 72076 Tübingen, Germany

Sven.Becker@med.uni-tuebingen.de

Members of the German Society for Applied Allergology (AeDA) (alphabetical order). Sven Becker, Klinik für Hals-, Nasen- und Ohrenheilkunde, Universität Tübingen, Tübingen, Deutschland; Ludger Klimek, Zentrum für Rhinologie und Allergologie Wiesbaden, Wiesbaden, Deutschland; Hans Merk, Abteilung Dermatologie \& Allergologie, RWTH Aachen, Deutschland; Johannes Ring, Haut- und Laserzentrum an der Oper, München; Wolfgang Wehrmann, Dermatologische Gemeinschaftspraxis Wehrmann, Münster, Deutschland.

\section{Members of the German Society of Oto-Rhino- Laryngology, Head and Neck Surgery (DGHNO) (alphabetical order). Thomas Deitmer, Deutsche Gesellschaft für Hals-, Nasen- und Ohrenheilkunde, Kopf- und Halschirurgie, Bonn, Deutschland; Stefan Plontke, Klinik und Poliklinik für Hals-Nasen-Ohren- Heilkunde, Kopf- und Hals-Chirurgie, Martin-Luther- Universität Halle-Wittenberg, Halle, Deutschland, President of the German Society of Oto-Rhino- Laryngology, Head and Neck Surgery (DGHNO).}

Funding. Open Access funding enabled and organized by Projekt DEAL.

\section{Declarations}

Conflict of interest. L. Klimek, R. Buhl, T. Deitmer, S. Plontke, W. Wehrmann, H. Merk, J. Ring and S. Becker declare that they have no competing interests.

For this article no studies with human participants or animals were performed by any of the authors. All studies performed were in accordance with the ethical standards indicated in each case.

The supplement containing this article is not sponsored by industry.

Open Access. This article is licensed under a Creative Commons Attribution 4.0 International License, which permits use, sharing, adaptation, distribution and reproduction in any medium or format, as long as you give appropriate credit to the original author(s) and the source, provide a link to the Creative Commons licence, and indicate if changes were made. The images or other third party material in this article are included in the article's Creative Commons licence, unless indicated otherwise in a credit line to the material. If material is not included in the article's Creative Commons licence and your intended use is not permitted by statutory regulation or exceeds the permitted use, you will need to obtain permission directly from the copyright holder. To view a copy of this licence, visit http://creativecommons.org/licenses/by/4.0/.

\section{References}

1. Klimek L, Becker S, Buhl R et al (2020) Positionspapier: Empfehlungen zur Behandlung der chronischen Rhinosinusitis während der COVID-19-Pandemie im deutschen Gesundheitssystem - Empfehlungen des Ärzteverbandes Deutscher Allergologen (AeDA) und der Deutschen Gesellschaft für HNO-Heilkunde, Kopfund Halschirurgie (DGHNO-KHC). Laryngorhinootologie 99:356-364. https://doi.org/10.1055/ a-1164-9696 (Diese Empfehlungen basieren auf dem EAACI Positionspapier "Treatment of chronic RhinoSinusitis with nasal polyps (CRSwNP) in the COVID-19 pandemics-An EAACI Position Paper", Allergy, 2020 und wurden auf die Situation im deutschen Gesundheitswesen angepasst.)

2. Klimek L, Förster-Ruhrmann U, Becker Set al (2020) Stellungnahme zur Anwendung von Glukokortikosteroiden bei entzündlichen Erkrankungen der oberen Atemwege (u.a. allergische Rhinitis/ chronische Rhinosinusitis) während der aktuellen COVID-19-Pandemie - Empfehlungen des Ärzteverbandes Deutscher Allergologen (AeDA), des Deutschen Berufsverbandes der HNO-Ärzte (BVHNO) und der AGs Klinische Immunologie, Allergologie und Umweltmedizin und Rhinologie und Rhinochirurgie der Deutschen Gesellschaft für HNO-Heilkunde, Kopf- und Halschirurgie (DGHNOKHC). Laryngorhinootologie 99:280-281. https:// doi.org/10.1055/a-1148-3553

3. Bölke G, Church MK, Bergmann K-C (2019) Comparison of extended intervals and dose reduction of omalizumab for asthma control. Allergo J Int 28:1-4. https://doi.org/10.1007/ s40629-018-0087-6

4. Hamelmann E (2018) Long-acting muscarinic antagonists for the treatment of asthma in children-a new kid in town. Allergo J Int 27:220-227. https://doi.org/10.1007/s40629018-0066-y

5. Ong KY (2019) What's new in the Global Initiative for Asthma 2018 report and beyond. Allergo J Int 28:63-72. https://doi.org/10.1007/s40629-0180079-6

6. Rothe T (2018) A Century of "intrinsic asthma" - a view on the development of phenotyping in asthma in the last 100 years. Allergo J Int 27:215-219

7. Sennekamp J (2014) Bronchitis and asthma in the setting of vitamin D deficiency. Allergo J Int 23:113-114. https://doi.org/10.1007/s40629014-0016-2

8. Buhl R, Bals R, Baur X et al (2021) S2k-Leitlinie zur Diagnostik und Therapie von Patienten mit Asthma-Addendum 2020. Pneumologie 75:191-200. https://doi.org/10.1055/a-13520296

9. Buhl R, Bals R, Baur X et al (2017) S2k-Leitlinie zur Diagnostik und Therapie von Patienten mit Asthma. Pneumologie 71:849-919. https://doi. org/10.1055/s-0043-119504

10. Klimek L, Bachert C, Pfaar O et al (2019) ARIA guideline 2019: treatment of allergic rhinitis in the German health system. Allergol Sel 3:22-50. https://doi.org/10.5414/ALX02120E
11. Klimek L, Casper I, Bergmann K-C et al (2020) Therapy of allergic rhinitis in routine care: evidence-based benefit assessment of freely combined use of various active ingredients. Allergo J Int 29:129-138. https://doi.org/10.1007/ s40629-020-00133-7

12. Bousquet J, Akdis C, Jutel M et al (2020) Intranasal corticosteroids in allergic rhinitis in COVID-19 infected patients: an ARIA-EAACI statement. Allergy. https://doi.org/10.1111/all.14302

13. Bousquet J, Jutel M, Akdis CA et al (2020) ARIAEAACl statement on asthma and COVID-19. Allergy 76:689-697. https://doi.org/10.1111/all.14471

14. Ramakrishnan S, Nicolau DV, Langford B et al (2021) Inhaled budesonide in the treatment of early COVID-19 (STOIC): a phase 2, open-label, randomised controlled trial. Lancet Respir Med. https://doi.org/10.1016/S2213-2600(21)00160-0

15. Dutile S, Kaptchuk TJ, Wechsler ME (2014) The placebo effect in asthma. Curr Allergy Asthma Rep 14:456. https://doi.org/10.1007/s11882-0140456-2

16. Frew AJ, Pfaar O (2018) Placebo effects in allergen immunotherapy: an experts' opinion. Allergo J Int 27:162-166. https://doi.org/10.1007/s40629018-0065-z

17. Yu L-M, Bafadhel M, Dorward J et al (2021) Inhaled budesonide for COVID-19 in people at higher risk of adverse outcomes in the community: interim analyses from the PRINCIPLE trial https://doi.org/ $10.1101 / 2021.04 .10 .21254672$

18. Jakob T, Klimek L (2020) Allergologie in Zeiten von Covid-19. Allergo J 29:3-3. https://doi.org/10. 1007/s15007-020-2538-x

19. Klimek L, Worm M, Lange L et al (2020) Management von Anaphylaxiegefährdeten Patienten während der Covid-19-Pandemie. Allergo J 29:16-26. https://doi.org/10.1007/s15007-0202618-y

20. Ring J, Beyer K, Biedermann Tet al (2021) Guideline (S2k) on acute therapy and management of anaphylaxis: 2021 update: S2k-Guideline of the German Society for Allergology and Clinical Immunology (DGAKI), the Medical Association of German Allergologists (AeDA), the Society of Pediatric Allergology and Environmental Medicine (GPA), the German Academy of Allergology and Environmental Medicine (DAAU), the German Professional Association of Pediatricians (BVKJ), the Society for Neonatology and Pediatric Intensive Care (GNPI), the German Society of Dermatology (DDG), the Austrian Society for Allergology and Immunology (ÖGAI), the Swiss Society for Allergy and Immunology (SGAI), the German Society of Anaesthesiology and Intensive Care Medicine (DGAI), the German Society of Pharmacology (DGP), the German Respiratory Society (DGP), the patient organization German Allergy and Asthma Association (DAAB), the German Working Group of Anaphylaxis Training and Education (AGATE). Allergo J Int 30:1-25. https://doi.org/10.1007/ s40629-020-00158-y

21. Skevaki C, Karsonova A, Karaulov A et al (2020) Asthma-associated risk for COVID-19 development. J Allergy Clin Immunol 146:1295-1301 https://doi.org/10.1016/j.jaci.2020.09.017

22. Dramburg S, Walter U, Becker S et al (2021) Telemedicine in allergology: practical aspects: a position paper of the Association of German Allergists (AeDA). Allergo J Int. https://doi.org/10. 1007/s40629-021-00167-5

23. Klimek L, Jakob T (2021) Darf's noch etwas mehr (Bürokratie und Regulierungswut) sein? Allergo J 


\section{Position Paper}

30:3-3. https://doi.org/10.1007/s15007-0214787-8

24. Klimek L, Pfaar O, Worm M (2020) Anwendung von Biologika bei allergischen und Typ2-entzündlichen Erkrankungen in der aktuellen COVID-19-Pandemie - ein Positionspapier von AeDA, DGAKI, GPA, ÖGAI, LGAI, ÖGP, ARIA und EAACI. Use of biologicals in allergic and type-2 inflammatory diseases in times of the current COVID-19 pandemic-Position paper of AeDA, DGAKI, GPA, ÖGAI, LGAI, ÖGP, ARIA und EAACI. AL 43:255

25. KlimekL, NovakN,HamelmannEetal (2021) Severe allergic reactions after COVID-19 vaccination with the Pfizer/BioNTech vaccine in Great Britain and USA. Allergo J Int 30:51-55. https://doi.org/10. 1007/s40629-020-00160-4 